\section{REFORMA DEL CASTILLO Y CAPILLA DE SANT SALVADOR DE PUIG - ALDER}

\section{REFORM OF THE CASTLE AND CHAPEL OF SANT SALVADOR PUIG - ALDER}

\section{Dr. Joan Curós}

Arquitecto, Universidad Politécnica de Cataluña, Barcelona, España joan.curos@upc.edu

\section{Xavier Ferrer}

Arquitecto, Universidad Politécnica de Cataluña, Barcelona, España. xaviferrer@gmail.com

\section{Resumen}

La obra restituye a la arquitectura originaria derribando a los elementos constructivos añadidos en posteriodad a su construcción inicial, los cuales desvirtuaban y desdibujaban a la edificación. Con esta intervención se obtiene una depuración volumétrica y paralelamente se destaca una penetrabilidad y una permeabilidad visual en la planta baja hasta llegar a la absorción del propio paisaje colindante al interior de la misma. La reforma aumenta la unidad y la cohesión del edificio dando continuidad a la cubierta del refugio, a lo largo de toda su longitud, lo cual conlleva a romper la simetría de los dos faldones en todo el edificio y dar cobijo a la terraza preexistente. Este aspecto se aprecia de manera notable en la fachada sur del castillo donde el edificio surge de entre las rocas, las cuales se prolongan en sus cerramientos.

En ello se plasma que menos es más.

\section{Abstract}

This work restores the original architecture by removing subsequent construction elements that distorted and blurred the building. The intervention clarifies the volume and simultaneously, brings out visual penetrability and permeability to the bottom floor, until the inner adjoining landscape is absorbed. The restoration increases the building's unity and consistency providing the shelter's cover with continuity along its entire length, thereby breaking the symmetry of the two gables and taking in the existing terrace. This aspect is notably appreciated in the castle's south façade, where the building emerges from the rocks that extend throughout the closures. This clearly expresses that "less is more".

\section{Ficha técnica}

Arquitecto

Joan Curós.

Xavier Ferrer.

Ubicación

\section{Cálculo Estructural}

Construcción

Superficie de terreno

Les Planes d'Hostoles. Girona. España.

Superficie de la obra : Miguel A. R. Nevado. Arquitecto.

Construcciones J. Pallas, S.L. Olot. Girona.

$4.036 \mathrm{~m}^{2}$

Materialidad predominante : piedra y madera

Presupuesto de la obra $: 77.786,80 €$

\section{Año proyecto}

2008.

Año construcción

2009.

Fotografías

Joan Curós.

Palabras clave: patrimonio, restauración, castillo, terraza.

Key words: heritage, restoration, castle, terrace.

"La buena arquitectura debería acoger al hombre, dejarle que viva y babite alli, y no abrumarle con su charla".

Peter Zumthor

\section{Descripción de la intervención_}

El edificio se halla situado en el noreste de España, concretamente en Cataluña a una altitud de $707 \mathrm{~m}$, sobre una colina al norte de la pequeña población de Les Planes d'Hostoles en la provincia de Girona.

El acceso es exclusivamente peatonal a través de un sendero que asciende por la vertiente noreste el cual se inicia aproximadamente en la cota 600, lugar por donde coincide con el camino que deriva de la población vecina de Sant Feliu de Pallerols siguiendo el Torrente de Bastons.

Los castillos de les Planes d'Hostoles - Castillo d'Hostoles y Castillo de PuigAlder- conjuntamente con el Castillo de Colltort, formaban en la época medieval la línea defensiva que separaba los obispados de las ciudades de Vic y Girona. Durante el siglo XV fue escenario de la revuelta organizada por los campesinos remenses, la primera que triunfó en Europa.

El Castillo de Puig-Alder está documentado que durante el año 1184 ya disponía de una capilla dedicada a Santo Salvador y años más tarde cuando el castillo fue perdiendo las funciones defensivas adquirió una función eclesiástica gracias a la capilla existente. El edificio pasó en distintas manos de propietarios a lo largo de su historia. Durante el siglo XVII existe documentación donde hubo distintos ermitaños. 
El castillo es de origen románico, aunque no se conserven trazas de esta época a causa de los terremotos ocurridos en los años 1428 y 1429. Su arquitectura responde a las modificaciones efectuadas a lo largo de la Baja Edad Media y Edad Moderna, cuando se amplió la capilla y se adaptó a las necesidades para poder vivir, con la existencia de distintas dependencias, como comedor, cocina, depósito para la recogida de las aguas pluviales, terraza.

Actualmente el Castillo de Puig-Alder es más conocido por la Ermita de Sant Salvador. Una parte de su interior está adaptado como pequeño refugio de montaña y la otra se encuentra la propia ermita en la cual se celebra culto una vez al año coincidiendo con la festividad del patrón.

La edificación actual está constituida por una volumetría principal de gran solidez que aloja a la ermita. Posteriormente se anexó frontalmente a ésta el porche y lateralmente el refugio con una terraza. Los últimos volúmenes añadidos fueron la cisterna, el horno y el baño, los cuales distorsionan notablemente la claridad volumétrica del conjunto de la edificación y entorpecen la espléndida percepción panorámica existente de los alrededores. La cisterna se halla construida justo delante del porche, donde impide parte de las visuales paisajísticas que presiden al norte, el horno se halla colateral a la entrada del refugio obstruyendo la mitad de un extraordinario arco en planta baja, el cual la otra mitad se hallaba tapiada conjuntamente con otro arco de la fachada oeste. El baño se encuentra en el lateral este de la capilla donde no permite el acceso de norte a sur o viceversa del exterior del edificio.

Atendiendo a estas incidencias el proyecto recupera la identidad del edificio original, derribando el volumen de la cisterna, el horno y el baño. También se derriban todas las tapias de los arcos y divisiones existentes en la planta baja del refugio para conseguir una transparencia y poder recuperar las extraordinarias visuales de las fachadas norte y sur. La cisterna como almacén de las aguas pluviales, éstas funcionarán con sistema de bombeo hacia la cocina del refugio y al baño. El baño se derriba el volumen lateral y se sitúa en la planta baja con acceso desde la fachada sur, adaptando una dependencia existente sin ningún uso.

La intervención de más notabilidad es la reforma casi integral de la terrazamirador del refugio orientada a sur, donde se prolonga la cubierta del mismo aumentando la unidad volumétrica del conjunto y dando al citado espacio unas características mucho más cálidas y confortables tanto en invierno que se encuentra resguardada, como en verano que protege del sol, convirtiéndose ésta en una dependencia más del refugio. Se ha restituido el mismo sistema constructivo existente de la cubierta y el pavimento se ha substituido la rasilla cerámica por tablas de madera. La nueva barandilla de madera se ha colocado tal como la preexistente.

El objetivo del proyecto ha sido depurar el volumen, dar más confortabilidad a la zona de estancia y paralelamente aumentar la cohesión de la volumetría para que las distintas etapas de crecimiento construidas incrementen su unidad y homogeneización en la edificación. El lenguaje arquitectónico del edificio mantiene un estrecho vínculo matérico con su entorno, como si un monumento rocoso emergiera entre las rocas. Esta percepción se plasma con gran alegoría en la fachada sur. ๑uS

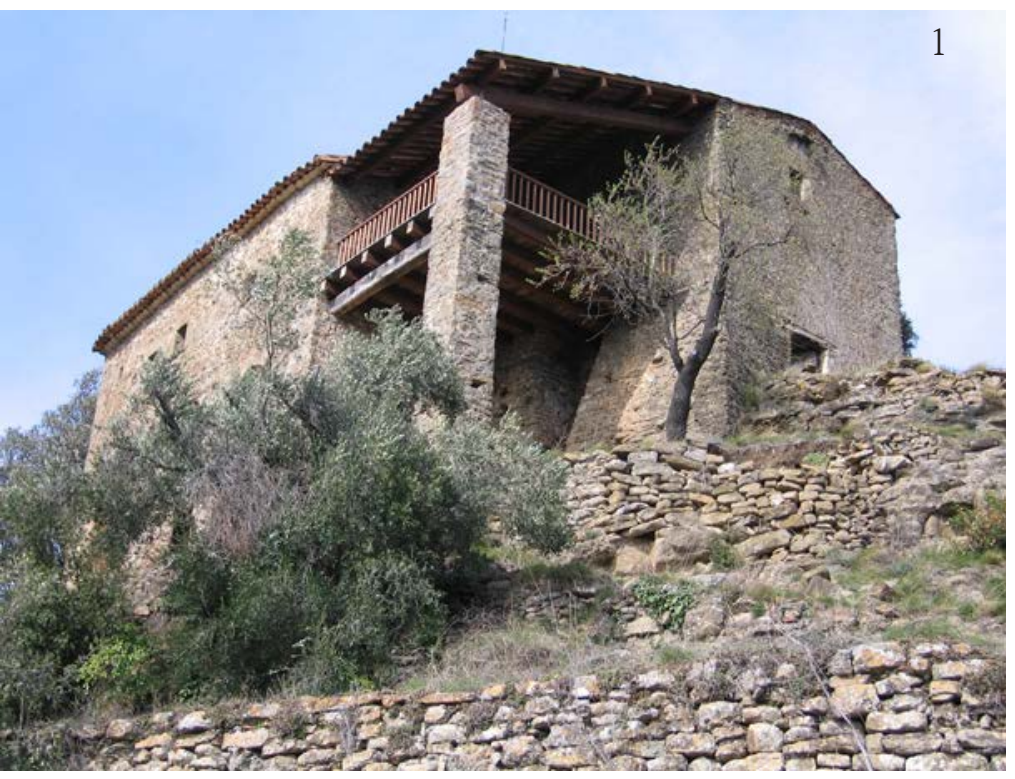

Imagen 2_Inserción del paisaje en planta baja del edificio (fuente: el autor).

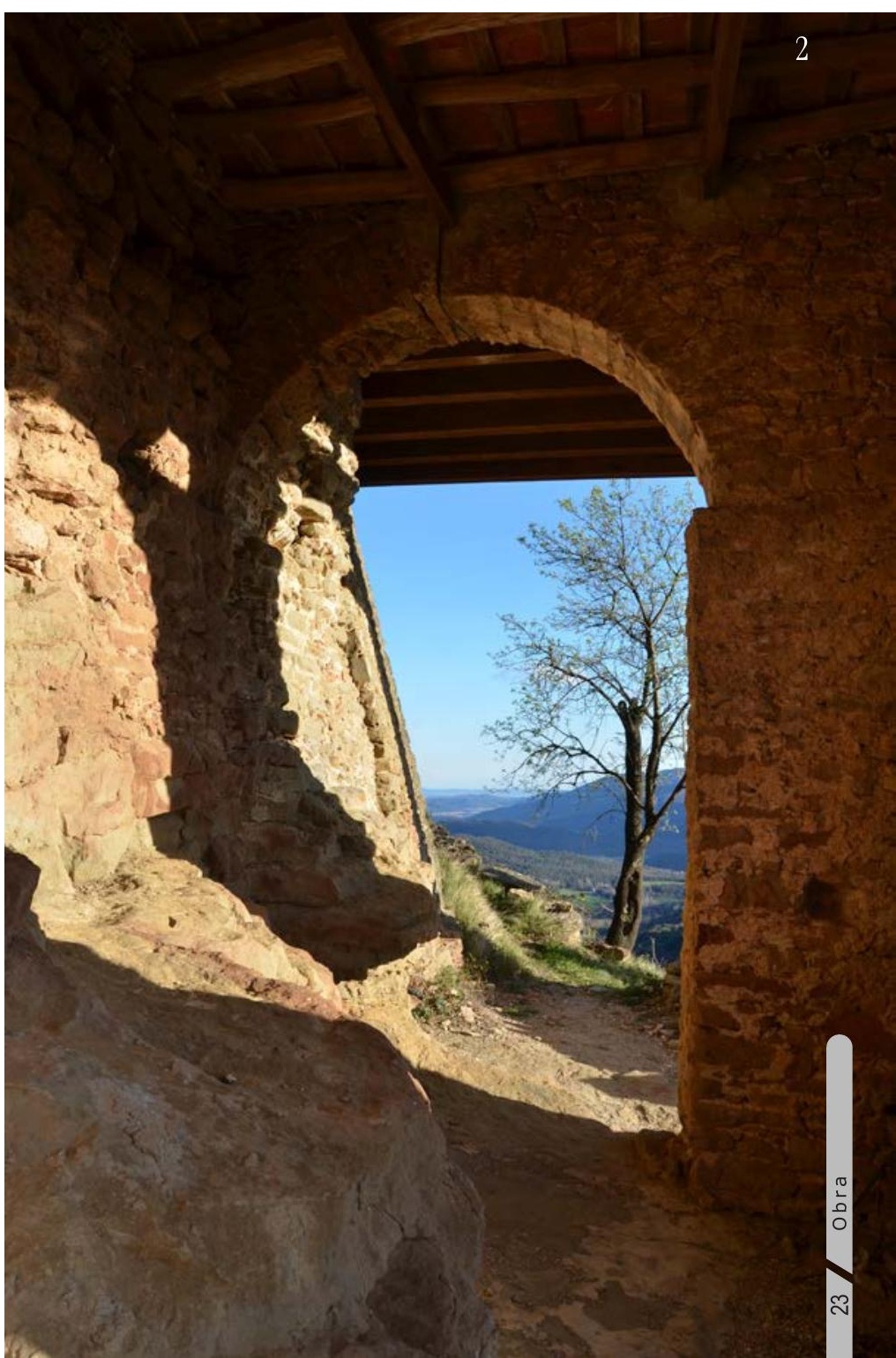




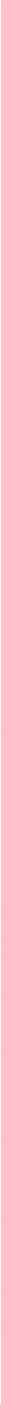

Imagen 3_ Percepción oeste desde la terraza (fuente: el autor). 


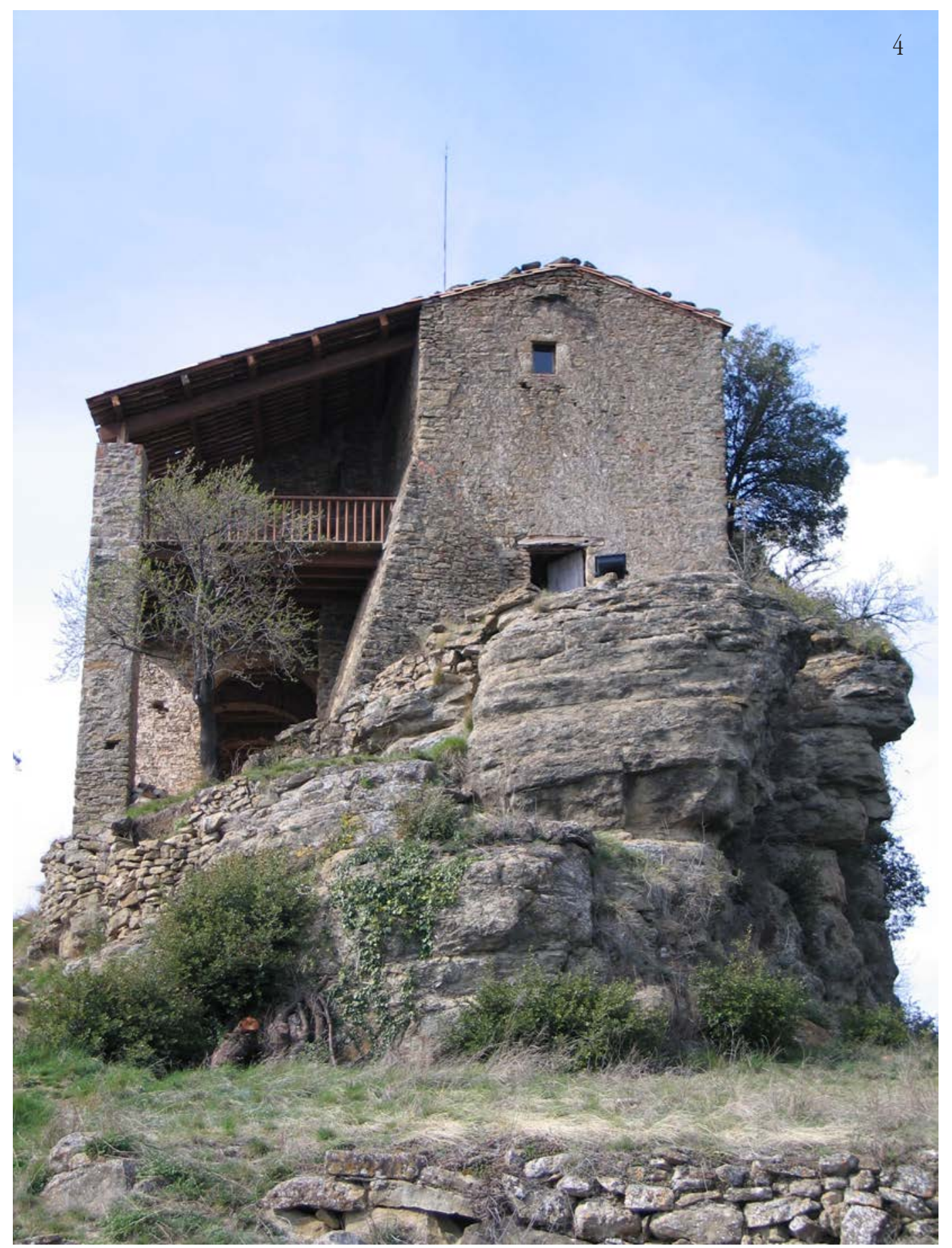

Imagen 4_Fachada sur (fuente: el autor). 

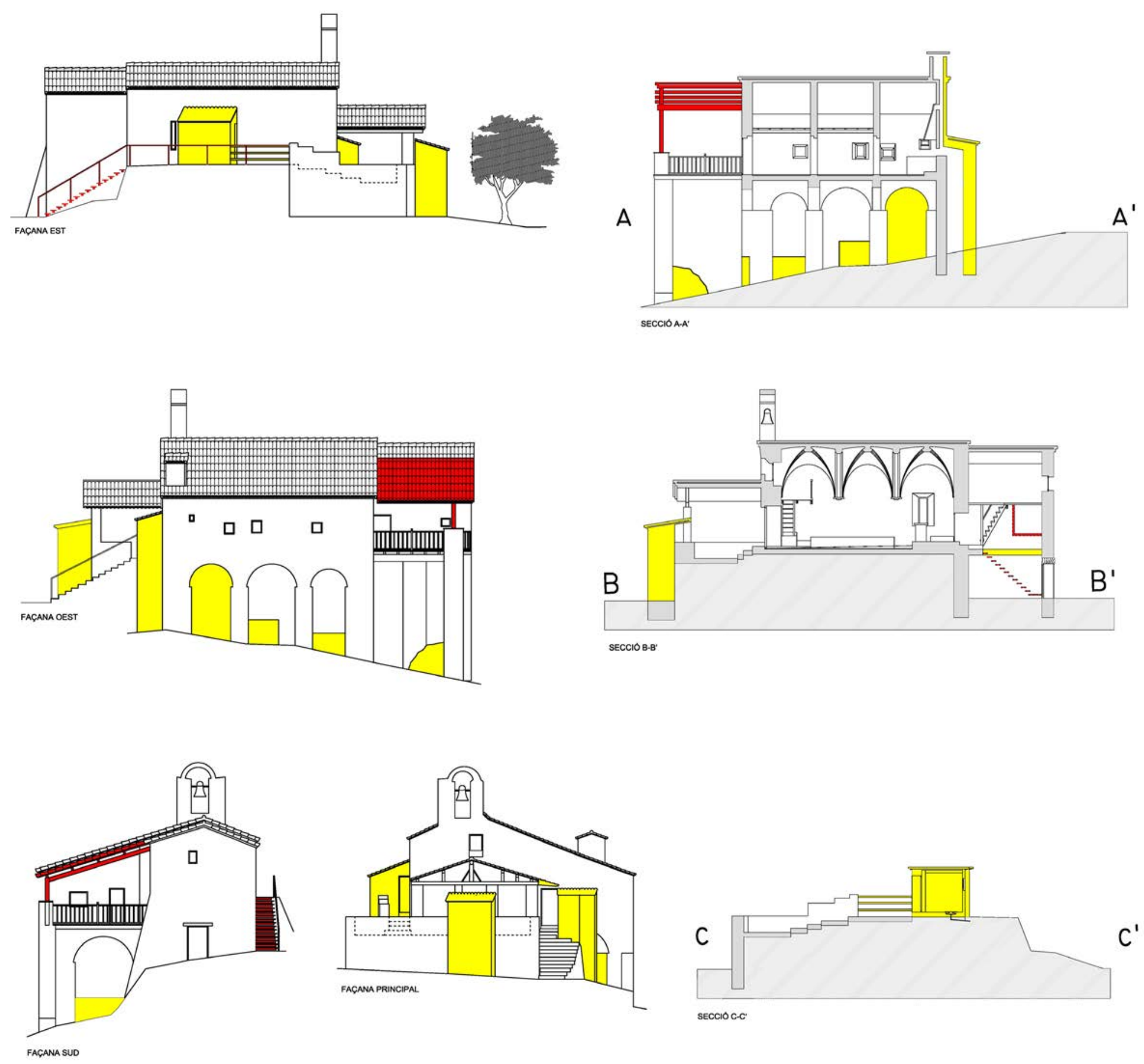

Elevaciones y cortes de Arquitectura 